\title{
Validation of the 21-gene test as a predictor of clinical response to neoadjuvant hormonal therapy for ER+, HER2-negative breast cancer: the TransNEOS study
}

\author{
Hiroji Iwata ${ }^{1}$ - Norikazu Masuda ${ }^{2} \cdot$ Yutaka Yamamoto $^{3} \cdot$ Tomomi Fujisawa $^{4} \cdot$ Tatsuya Toyama $^{5}$. \\ Masahiro Kashiwaba ${ }^{6} \cdot$ Shoichiro Ohtani $^{7} \cdot$ Naruto Taira $^{8} \cdot$ Takehiko Sakai $^{9} \cdot$ Yoshie Hasegawa $^{10} \cdot$ Rikiya Nakamura $^{11}$. \\ Hiromitsu Akabane ${ }^{12}$. Yukiko Shibahara ${ }^{13}$. Hironobu Sasano ${ }^{13} \cdot$ Takuhiro Yamaguchi $^{13} \cdot$ Kentaro Sakamaki $^{14}$. \\ Helen Bailey ${ }^{15}$. Diana B. Cherbavaz ${ }^{15}$. Debbie M. Jakubowski ${ }^{15} \cdot$ Naoko Sugiyama $^{15} \cdot$ Calvin Chao $^{15} \cdot$ Yasuo Ohashi $^{16}$
}

Received: 27 July 2018 / Accepted: 6 September 2018 / Published online: 21 September 2018

(c) The Author(s) 2018

\begin{abstract}
Purpose The Recurrence Score test is validated to predict benefit of adjuvant chemotherapy. TransNEOS, a translational study of New Primary Endocrine-therapy Origination Study (NEOS), evaluated whether Recurrence Score results can predict clinical response to neoadjuvant letrozole.

Methods NEOS is a phase 3 clinical trial of hormonal therapy \pm adjuvant chemotherapy for postmenopausal patients with ER+, HER2-negative, clinically node-negative breast cancer, after six months of neoadjuvant letrozole and breast surgery. TransNEOS patients had tumors $\geq 2 \mathrm{~cm}$ and archived core-biopsy samples taken before neoadjuvant letrozole and subsequently sent for Recurrence Score testing. The primary endpoint was to evaluate clinical (complete or partial) response to neoadjuvant letrozole for $\mathrm{RS}<18$ versus $\mathrm{RS} \geq 31$. Secondary endpoints included evaluation of clinical response and rate of breast-conserving surgery (BCS) by continuous Recurrence Score result, ESRI and PGR single-gene scores, and ER genegroup score.

Results Of 295 TransNEOS patients (median age 63 years; median tumor size $25 \mathrm{~mm}$; $66 \%$ grade 1), $53.2 \%$ had RS $<18$, $28.5 \%$ had RS18-30, and $18.3 \%$ had $\mathrm{RS} \geq 31$. Clinical response rates were $54 \%$ (RS $<18$ ), $42 \%$ ( $\mathrm{RS} 18-30$ ), and $22 \%$ $(\mathrm{RS} \geq 31)$. A higher proportion of patients with $\mathrm{RS}<18$ had clinical responses $(p<0.001 \mathrm{vs.} \mathrm{RS} \geq 31)$. In multivariable analyses, continuous Recurrence Score result $(p<0.001), E S R 1$ score $(p=0.049), P G R$ score $(p<0.001)$, and ER gene-group score $(p<0.001)$ were associated with clinical response. Recurrence Score group was significantly associated with rate of BCS after neoadjuvant treatment ( $\mathrm{RS}<18$ vs. $\mathrm{RS} \geq 31, p=0.010$ ).

Conclusion The Recurrence Score test is validated to predict clinical response to neoadjuvant letrozole in postmenopausal patients with ER+, HER2-negative, clinically node-negative breast cancer.
\end{abstract}

Keywords Breast cancer $\cdot$ Hormonal therapy $\cdot$ Neoadjuvant $\cdot$ Oncotype DX $\cdot$ Recurrence score

$\begin{array}{ll}\text { Abbreviations } \\ \text { BCS } & \text { Breast-conserving surgery } \\ \text { CI } & \text { Confidence interval } \\ \text { CR } & \text { Complete response } \\ \text { ER } & \text { Estrogen receptor protein }\end{array}$

Electronic supplementary material The online version of this article (https://doi.org/10.1007/s10549-018-4964-y) contains supplementary material, which is available to authorized users.

Hiroji Iwata

hiwata@aichi-cc.jp

Extended author information available on the last page of the article
ESR1 Estrogen receptor 1 gene

HER2 Human epidermal growth factor 2 protein

IHC Immunohistochemistry

MRI Magnetic resonance imaging

NEOS New Primary Endocrine Therapy Origination Study

NSABP National Surgical Adjuvant Breast and Bowel Project

PD Progressive disease

PGR Progesterone receptor gene

$\mathrm{PgR} \quad$ Progesterone receptor protein

PR Partial response

RS Recurrence Score result 


$\begin{array}{ll}\text { RT-PCR } & \begin{array}{l}\text { Reverse transcription-polymerase chain } \\ \text { reaction }\end{array} \\ \text { SD } & \text { Stable disease } \\ \text { st dev } & \text { Standard deviation }\end{array}$

\section{Introduction}

Neoadjuvant therapy for locally advanced breast cancer has the potential to improve rates of breast-conserving surgery (BCS), permit the assessment of patients' primary tumor response to systemic therapy, and reduce rates of distant metastases by as much as that observed with adjuvant approaches [1-6]. Clinical and pathological complete responses (CR) to neoadjuvant therapy are associated with improved clinical outcomes, and both are considered to be valid surrogates of clinical outcomes for some types of breast cancer [1, 6, 7].

Previous studies have demonstrated higher rates of clinical and pathological CR to neoadjuvant chemotherapy in high-grade tumors and tumors with higher levels of Ki-67 protein expression, but lower rates of response in tumors positive for estrogen receptor (ER) protein expression [7-9]. Historically, neoadjuvant hormonal therapy was reserved only for patients who were not candidates for neoadjuvant chemotherapy or surgery. Studies conducted since 2001, however, have demonstrated that neoadjuvant hormonal therapy can yield clinically meaningful response rates in more general populations of patients with ER + breast cancer [10-16]. Therefore, many patients with locally advanced $\mathrm{ER}+$ breast cancer may be considered for neoadjuvant hormonal therapy, as a viable means to achieve clinical response and improve rates of BCS [12-19]. As in the adjuvant setting, however, response to neoadjuvant hormonal therapy can vary across patients with ER + breast cancer [20]. Thus, the capacity to select patients who are more likely to benefit from neoadjuvant hormonal therapy would represent an advance in the clinical management of breast cancer.

The Oncotype DX Breast Recurrence Score $\AA$ test is a validated clinical tool that predicts benefit of adjuvant chemotherapy in patients with ER+, HER2-negative, node-negative [21-25], and node-positive [24, 26] early breast cancer who receive five years of hormonal therapy. In addition, the Recurrence Score test is validated to predict distant recurrence in patients treated with adjuvant hormonal therapy. The clinical validation study used samples from the National Surgical Adjuvant Breast and Bowel Project (NSABP) B-14 trial to show that the Recurrence Score ${ }^{\circledR}$ (RS) results quantified the likelihood of distant recurrence in patients with node-negative, ER + breast cancer who received tamoxifen [21].

Previous studies suggested that the Recurrence Score test might be useful in the neoadjuvant setting. Studies have demonstrated a relationship between the Recurrence Score result and response to neoadjuvant chemotherapy, with clinical or pathological CR more likely achieved in patients with higher Recurrence Score results [27-33]. Other studies have shown a correlation between low Recurrence Score results ( RS $<18$ ) and greater likelihood of response to neoadjuvant hormonal therapy [34, 35]. In one study of 43 postmenopausal women with $\mathrm{ER}+$, progesterone receptor-positive $(\mathrm{PgR}+)$ breast cancer who received neoadjuvant tamoxifen or anastrozole for four months, the rate of clinical response [CR + PR (partial response)] was $64 \%, 31 \%$, and $31 \%$ for patients with $\mathrm{RS}<18, \mathrm{RS} 18-30$, and $\mathrm{RS} \geq 31$, respectively [34]. In another study of 64 women with ER + breast cancer who received 16-24 weeks of neoadjuvant exemestane, the rate of clinical response was $59 \%$ for patients with RS $<18$ and $20 \%$ for patients with $\mathrm{RS} \geq 31(p=0.015)$. Rates of BCS were $91 \%$ with $\mathrm{RS}<18$ and $47 \%$ with $\mathrm{RS} \geq 31(p=0.003)$ [35]. Together, these study findings suggest that the Recurrence Score test could have utility in selecting patients for appropriate neoadjuvant therapy.

The New Primary Endocrine-Therapy Origination Study (NEOS), a phase 3 trial initiated in 2008, evaluated diseasefree survival of postmenopausal patients with ER+, HER2negative, node-negative, non-metastatic primary breast cancer who were randomized to adjuvant hormonal therapy with or without chemotherapy based on clinical response (CR, PR, or stable disease [SD]) to 24-28 weeks of neoadjuvant letrozole treatment. Surgery was performed before initiation of specified adjuvant treatment (Supplemental Fig. 1) [36]. Herein we report the findings of TransNEOS, a translational study of NEOS that was prospectively designed to evaluate the utility of the Recurrence Score test to predict clinical response to neoadjuvant hormonal therapy and successful BCS in postmenopausal women with ER+, HER2-negative, clinically node-negative breast cancer.

\section{Methods}

\section{Study patients}

Patients eligible for the TransNEOS study were previously enrolled in the parent NEOS study and were recruited from the 25 NEOS study centers with the highest patient enrollment. Eligible patients gave informed consent. They were postmenopausal women $<75$ years of age with T1c$\mathrm{T} 2(\geq 2 \mathrm{~cm}$ in the largest dimension, as measured by magnetic resonance imaging [MRI] and/or computed tomography scan), clinically node-negative, non-metastatic, ER+, HER2-negative invasive breast cancer who received neoadjuvant letrozole. Eligible patients had core-biopsy samples taken before neoadjuvant treatment that were later sent for Recurrence Score testing (Genomic Health, Inc., Redwood 
City, CA). Patients with no Recurrence Score results, no tumor block available, no or insufficient tumor in block as determined by a pathologist at Genomic Health in accordance with standard operating procedures, or insufficient or inadequate RNA for testing were excluded. Unique patient and specimen identifiers were assigned by the principal investigator and blinded to Genomic Health.

\section{Study protocol}

All patients included in the TransNEOS study received 24-28 weeks of neoadjuvant letrozole per the NEOS study protocol. Clinical response to neoadjuvant letrozole was assessed by mono-dimensional measurement of the largest diameter of the target tumor by MRI or computed tomography scan at baseline and at the conclusion of neoadjuvant treatment. Complete response (CR) was defined if the target tumor disappeared, partial response (PR) if the largest diameter of the target tumor was reduced by $\geq 30 \%$ from baseline, stable disease (SD) if the largest diameter of the target tumor was reduced by $<30 \%$ or increased by $<20 \%$ from baseline, and progressive disease (PD) if the largest diameter of the target tumor increased by $\geq 20 \%$ from baseline. Clinical response rate was defined as the sum of the rates of CR and PR. Recurrence Score testing was performed in a central laboratory (Genomic Health, Inc., Redwood City, CA) on RNA extracted from formalin-fixed paraffin-embedded core-biopsy samples, as previously described [21]. Recurrence Score results, single-gene results for estrogen receptor (ESR1), progesterone receptor (PGR), and HER2 (ERBB2), and gene-group scores for the ER gene-group (ESRI, PGR, $B C L 2, S C U B E 2)$ and proliferation gene-group (BIRC5, MKI67, MYBL2, CCNB1, AURKA) were reported as values of the Recurrence Score test. Standard Recurrence Score risk categories were used: RS $<18$, RS18-30, and RS $\geq 31$. Both local and central pathology determinations of ER (immunohistochemistry [IHC] or Allred score), PgR (IHC or Allred score), and HER2 (IHC and/or fluorescent in situ hybridization), and central pathology determination of Ki-67 (IHC) were performed on all tumor samples using standard techniques. BCS candidacy before neoadjuvant treatment was determined by the treating surgeon. The study was reviewed and approved by each institution's review board and/or ethics committee.

\section{Study endpoints}

The primary endpoint was to compare the clinical response $(\mathrm{CR}+\mathrm{PR})$ to neoadjuvant letrozole between patients with $\mathrm{RS}<18$ and $\mathrm{RS} \geq 31$. Secondary clinical endpoints included description of the relationship between the clinical response to neoadjuvant letrozole and (a) continuous Recurrence Score result; (b) ESR1, PGR, and ER gene-group scores by
RT-PCR; (c) Ki-67 by IHC; and (d) proliferation gene-group score by RT-PCR. In addition, correlations between Ki67 by IHC and (a) Recurrence Score results and (b) proliferation gene-group score by RT-PCR were examined.

Secondary surgical endpoints included description of the relationship between the rate of BCS after neoadjuvant letrozole and (a) continuous Recurrence Score result; (b) categorical Recurrence Score groups ( $\mathrm{RS}<18$ and $\mathrm{RS} \geq 31$ ); and (c) ESRI, PGR, and ER gene-group scores by RT-PCR. In addition, the relationships between change in treatment from mastectomy to BCS after neoadjuvant letrozole and (a) continuous Recurrence Score result and (b) categorical Recurrence Score groups ( $\mathrm{RS}<18$ and $\mathrm{RS} \geq 31$ ) were evaluated.

\section{Statistical analysis}

All analyses were prespecified and included patients with reportable values of the associated variables. All hypothesis tests were reported using two-sided $p$ values, and $p$ values $<0.05$ were considered statistically significant. The clinical and pathological characteristics of the patients were reported descriptively. Continuous variables were summarized as mean (standard deviation) and/or median (range). Categorical variables were reported as numbers and proportions (percentage). A $\chi^{2}$ test was used to determine if the proportion of patients with clinical response in the $\mathrm{RS}<18$ group was significantly higher than the proportion with clinical response in the $\mathrm{RS} \geq 31$ group. For small expected group counts, Fisher's exact test was used. A logistic regression model was used to describe the relationship between clinical response and the Recurrence Score result, the continuous ESRI result by RT-PCR, the continuous $P G R$ result by RT-PCR, the ER gene-group score, the proliferation gene-group score, and Ki-67 percent-staining. Single-gene and gene-group scores were standardized to represent the proportional increase in odds of one standard deviation. These analyses were performed with and without adjustment for clinical covariates. The Spearman correlation between Ki-67 percent-staining and Recurrence Score result (95\% confidence interval [CI]), and between $\mathrm{Ki}-67$ percent-staining and proliferation gene-group score $(95 \% \mathrm{CI})$ were reported. The proportion of patients in the RS $<18$, RS18-30, and RS $\geq 31$ groups who were candidates for BCS before and who actually received BCS after neoadjuvant treatment, and who changed treatment from mastectomy to BCS before and after neoadjuvant treatment, was calculated. (Information about BCS candidacy after neoadjuvant treatment was not collected, only actual surgery received.) A logistic regression model was used to describe the relationship between Recurrence Score group and (a) changes in BCS candidacy before neoadjuvant treatment; and (b) BCS received after 
neoadjuvant treatment. A logistic regression model was used to describe the relationship between the rate of BCS after neoadjuvant treatment and (a) continuous ESRl result by RT-PCR; (b) continuous PGR result by RT-PCR; and (c) continuous ER gene-group score by RT-PCR. These analyses were performed with and without adjustment for clinical covariates. As ESRI and PGR are components of the Recurrence Score result, each variable was considered in separate models to avoid issues with collinearity. All analyses were performed in SAS 9.4 (SAS Institute Inc., Cary, NC).

\section{Results}

\section{Characteristics of the patients}

In total, 333 core-biopsy samples were submitted for Recurrence Score testing. Of these, 38 samples were excluded for reasons of insufficient RNA or sample quality $(n=18)$, incorrect tumor type or insufficient tumor $(n=10)$, specimen failure $(n=6)$, and clinical ineligibility $(n=4)$ (Fig. 1). Characteristics of the TransNEOS study cohort $(N=295)$ are summarized in Table 1 . Median Recurrence Score result was RS17 (range RS0-68); 157

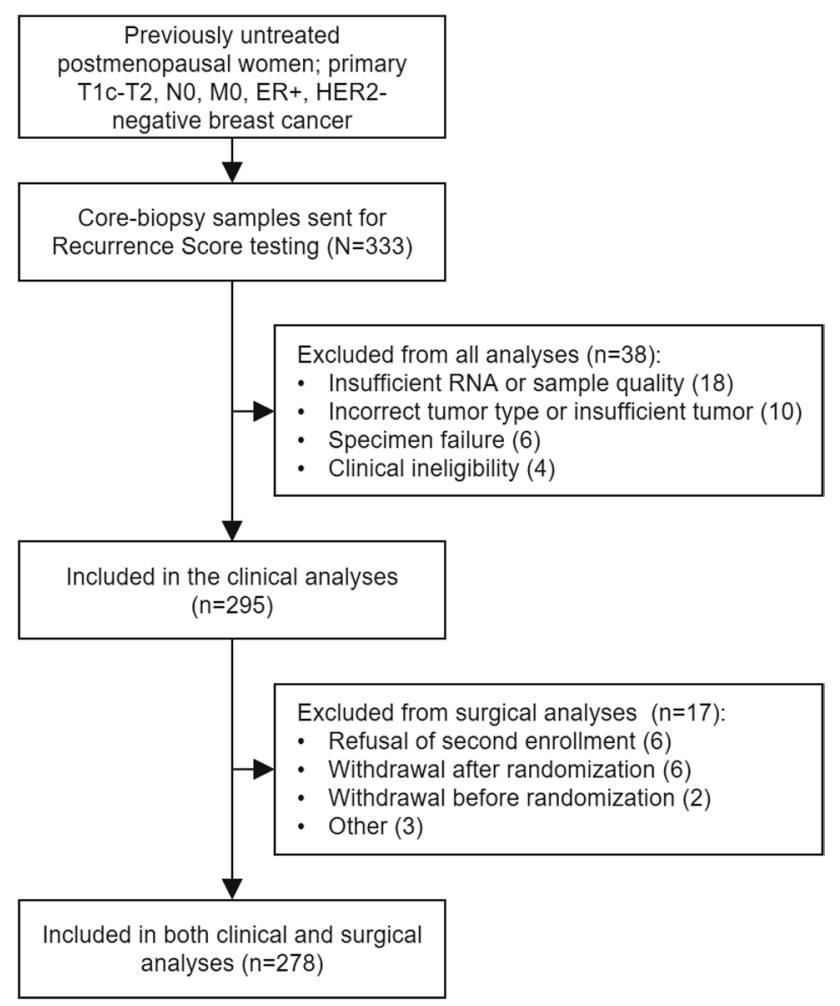

Fig. 1 REMARK diagram
(53.2\%) had RS $<18,84$ (28.5\%) had RS18-30, and 54 (18.3\%) had $\mathrm{RS} \geq 31$.

\section{Clinical response to neoadjuvant letrozole by Recurrence Score group}

The prespecified primary endpoint was met: Recurrence Score group ( $\mathrm{RS}<18$ vs. RS $\geq 31$ ) was significantly associated with the rate of clinical response $\left(\chi^{2}\right.$ test, $\left.p<0.001\right)$. Among patients with RS $<18$, RS 18-30, and RS $\geq 31$, rate of clinical response was $55 \%, 42 \%$, and $22 \%$, respectively. With the RS18-30 group included, Recurrence Score group remained significantly associated with the rate of clinical response (Cochran-Armitage trend test, $p<0.001)$. At $<1 \%$, patients with $\mathrm{RS}<18$ had the lowest rate of $\mathrm{PD}$, compared with patients with RS18-30 (4\% $\mathrm{PD}$ ) and $\mathrm{RS} \geq 31$ (17\% PD) (Fisher's exact test, $p<0.001$; Fig. 2).

\section{Univariable analysis of clinical response to neoadjuvant letrozole}

Univariable logistic regression analysis showed that continuous Recurrence Score result $(p<0.001), E S R 1$ result by RT-PCR $(p=0.019), P G R$ result by RT-PCR $(p<0.001)$, and ER gene-group score $(p<0.001)$ were significant predictors of clinical response to neoadjuvant letrozole (Supplemental Table 1). Neither the proliferation gene-group score nor Ki-67 percent-staining by IHC predicted clinical response (Supplemental Table 1).

\section{Multivariable analysis of clinical response to neoadjuvant letrozole, controlling for clinical factors}

In a multivariable logistic regression model, the continuous Recurrence Score result remained a significant predictor of clinical response after controlling for patient age, tumor size, and tumor grade (Table 2); odds ratio (95\% CI) was 0.06 (0.02 to 0.18) (profile likelihood test, $p<0.001$ ). Because ESR 1 by RT-PCR, PGR by RT-PCR, and ER gene-group score represent single-variable (individual) components of the Recurrence Score algorithm, each was considered individually in separate multivariable analyses (Table 3). In separate multivariable models controlling for age, tumor size, and tumor grade, ESRl by RT-PCR, $P G R$ by RT-PCR, and ER gene-group score were significant predictors of clinical response. Both $P G R$ by RT-PCR and ER gene-group score were stronger predictors of clinical response than ESRI by RT-PCR (Table 3). 
Table 1 Patient demographics and disease characteristics $(N=295)$

\begin{tabular}{|c|c|c|}
\hline Variable & Statistic & Result \\
\hline \multirow[t]{4}{*}{ Age, years } & Median (range) & $63(49-75)$ \\
\hline & $\leq 60$ & $94(31.9 \%)$ \\
\hline & $>60$ to 70 & $169(57.3 \%)$ \\
\hline & $>70$ & $32(10.8 \%)$ \\
\hline \multirow[t]{2}{*}{ T-stage } & $\mathrm{T} 1 \mathrm{c}$ & $44(14.9 \%)$ \\
\hline & $\mathrm{T} 2$ & $251(85.1 \%)$ \\
\hline \multirow[t]{4}{*}{ Nuclear grade } & 1 & $195(66.1 \%)$ \\
\hline & 2 & $59(20.0 \%)$ \\
\hline & 3 & $27(9.2 \%)$ \\
\hline & Missing & $14(4.7 \%)$ \\
\hline Tumor size, mm & Median (range) & $25(20-65)$ \\
\hline Ki-67 by IHC, $\%$ & Median (range) & $16.2(0.0,82.5)$ \\
\hline \multirow[t]{4}{*}{ Ki-67 category } & $<10 \%$ & $86(29.2 \%)$ \\
\hline & $10-30 \%$ & $123(41.7 \%)$ \\
\hline & $>30 \%$ & $61(20.7 \%)$ \\
\hline & Missing & $25(8.5 \%)$ \\
\hline \multirow[t]{2}{*}{ ESRl by RT-PCR } & Median (range) & $11.7(5.7-14.6)$ \\
\hline & Mean (st dev) & $11.5(1.3)$ \\
\hline \multirow[t]{2}{*}{ ER category, determined by RT-PCR } & Positive $(\geq 6.5)$ & $293(99.3 \%)$ \\
\hline & Negative $(<6.5)$ & $2(<1.0 \%)$ \\
\hline \multirow[t]{2}{*}{$P G R$ by RT-PCR } & Median (range) & $7.1(2.6-11.4)$ \\
\hline & Mean (st dev) & $6.7(2.0)$ \\
\hline \multirow[t]{2}{*}{ PgR category, determined by RT-PCR } & Positive $(\geq 5.5)$ & $211(71.5 \%)$ \\
\hline & Negative $(<5.5)$ & $84(28.5 \%)$ \\
\hline \multirow[t]{3}{*}{ HER 2 category, determined by RT-PCR } & Negative $(<10.7)$ & $235(79.7 \%)$ \\
\hline & Positive $(\geq 11.5)$ & $9(3.1 \%)$ \\
\hline & Equivocal (10.7 to < 11.5 ) & $51(17.3 \%)$ \\
\hline Recurrence Score result & Median (range) & $17(0-68)$ \\
\hline
\end{tabular}

$E R$ estrogen receptor, $H E R 2$ human epidermal growth factor receptor 2, $I H C$ immunohistochemistry, $P g R$ progesterone receptor, $R T$-PCR reverse transcription-polymerase chain reaction, st dev standard deviation

\section{Association of Recurrence Score Group With BCS candidacy before and rate of BCS after neoadjuvant letrozole}

Patients in the $\mathrm{RS}<18$ group were more likely than patients in the RS $\geq 31$ group to convert from BCS noncandidates to BCS recipients following neoadjuvant letrozole. Recurrence Score group was not associated with BCS candidacy before treatment $(p=0.878$; Table 4$)$. After neoadjuvant letrozole treatment, however, Recurrence Score group was significantly associated with BCS received $(p=0.009)$. Among patients with $\mathrm{RS}<18$ and both pre- and post-treatment data available, pre-treatment surgery recommendation significantly differed from posttreatment surgery received (McNemar's test $p<0.001$ ), whereas there was no significant change among patients with $\mathrm{RS} \geq 31$ ( $p=0.075$; Supplemental Table 2$)$.

\section{Discussion}

We report the findings of TransNEOS, the largest study to date to evaluate the relationship between Recurrence Score results and clinical response to neoadjuvant hormonal therapy. Recurrence Score group was shown to be significantly associated with clinical response to neoadjuvant letrozole, meeting the prespecified primary endpoint of the study. Among patients with large tumors $(\geq 2 \mathrm{~cm}), 54 \%$ of those with $\mathrm{RS}<18$ achieved CR or PR with neoadjuvant letrozole, and 79\% were BCS recipients, including many who were BCS noncandidates before neoadjuvant treatment. In contrast, patients with $\mathrm{RS} \geq 31$ had a higher rate of $\mathrm{PD}$ with neoadjuvant letrozole. (Patients in TransNEOS with PD on neoadjuvant letrozole were discontinued and subsequently received chemotherapy of physician's choice, either before or after surgery.) Multivariable analyses showed that 


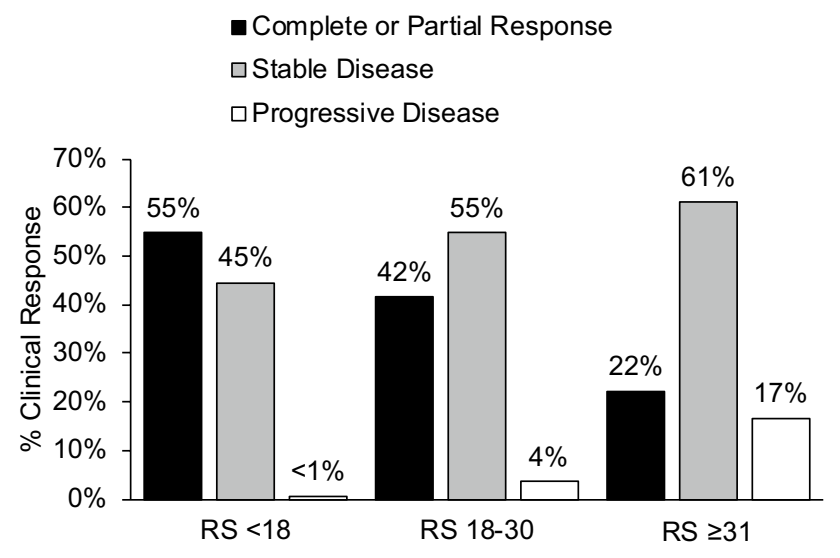

\begin{tabular}{|l|c|c|c|c|}
\hline $\begin{array}{l}\text { Clinical } \\
\text { Response, } \mathbf{n}\end{array}$ & $\mathbf{R S}<\mathbf{1 8}$ & $\mathbf{R S 1 8 - 3 0}$ & $\mathbf{R S ~} \geq \mathbf{3 1}$ & Total \\
\hline CR + PR & 86 & 35 & 12 & 133 \\
\hline SD & 70 & 46 & 33 & 149 \\
\hline PD & 1 & 3 & 9 & 13 \\
\hline Total & 157 & 84 & 54 & 295 \\
\hline
\end{tabular}

Fig. 2 Percent clinical response to neoadjuvant letrozole by Recurrence Score Group $(N=295)$; $C R$ complete response, $P D$ progressive disease, $P R$ partial response, $R S$ Recurrence Score, $S D$ stable disease

Table 2 Multivariable analysis ${ }^{\mathrm{a}}$ of clinical response, controlling for clinical factors $(N=281)$

\begin{tabular}{llc}
\hline Variable & Odd ratio $(95 \%$ CI) & $p$ value* \\
\hline $\begin{array}{l}\text { Recurrence Score result (per } \\
\text { 50-unit increase }\end{array}$ ) & $0.06(0.02,0.18)$ & $<0.001$ \\
Age (years) & $1.00(0.96,1.05)$ & 0.854 \\
Baseline tumor size (mm) & $1.00(0.96,1.03)$ & 0.786 \\
Grade & & \\
1 versus 3 & $0.44(0.17,1.09)$ & 0.074 \\
2 versus 3 & $0.81(0.29,2.19)$ & 0.671 \\
\hline
\end{tabular}

CI confidence interval

* $p$ value based on the profile likelihood test

${ }^{a} E S R 1, P G R$, and ER gene-group were not included in the prespecified multivariable analysis because they represent individual gene components of the Recurrence Score algorithm

${ }^{\mathrm{b}}$ Statistics were calculated per 50-unit change in Recurrence Score result to facilitate comparison with results of the original validation studies

the Recurrence Score result significantly predicted clinical response to neoadjuvant hormonal therapy, even after adjustment for clinical covariates (age, tumor size, and tumor grade). Tumor grade, Ki-67 by IHC, and proliferation gene-group score were not predictive of clinical response to neoadjuvant letrozole. Our study thereby validates the Recurrence Score test as a predictor of clinical response to six months of neoadjuvant letrozole in postmenopausal patients with ER+, HER2-negative, clinically node-negative, non-metastatic primary early breast cancer.

Validation of the Recurrence Score test as a predictor of clinical response to neoadjuvant hormonal therapy represents an important milestone for patients with large, hormone receptor-positive $(\mathrm{HR}+)$ breast tumors. Our findings support the utility of the Recurrence Score test to identify patients with $\mathrm{HR}+$ breast cancer who may be BCS noncandidates initially because of large tumor size but may convert to BCS candidates with neoadjuvant hormonal therapy. This could minimize exposure of patients to chemotherapy and its associated toxicities. The TransNEOS findings complement those of previous studies suggesting that the Recurrence Score test may help guide decisions about neoadjuvant chemotherapy [27-33]. In the Pivot and Yardley studies of neoadjuvant chemotherapy, the rate of pathologic CR was $26 \%(p=0.02)$ and $30 \%(p=0.002)$, respectively, among patients with RS $\geq 31$ but $0 \%$ among patients with $\mathrm{RS}<18$ [30, 31]. Recently, Bear and colleagues assessed the feasibility of using Recurrence Score results to guide neoadjuvant systemic therapy [27]. Patients with large $(\geq 2 \mathrm{~cm}) \mathrm{HR}+$, HER2-negative breast cancers who were BCS noncandidates were assigned neoadjuvant therapy based on Recurrence Score results: $\mathrm{RS}<11$ received hormonal therapy, $\mathrm{RS} \geq 26$ received chemotherapy, and RS11-25 were randomized to hormonal therapy or chemotherapy. Rates of clinical response $(\mathrm{CR}+\mathrm{PR})$ were significantly associated with Recurrence Score group $(p=0.049)$ : $83 \%$ for $\mathrm{RS}<11$ (hormonal therapy alone), 50\% for RS11-25 (hormonal therapy), 73\% for RS11-25 (chemotherapy), and 93\% for $\mathrm{RS} \geq 26$ (chemotherapy). Rates of successful BCS after neoadjuvant systemic therapy were not significantly different across Recurrence Score groups: $75 \%$ for RS $<11$, $72 \%$ for RS11-25 (hormonal therapy), 64\% for RS11-25 (chemotherapy), and 57\% for RS $\geq 26$ [27]. Previously published data on the Recurrence Score test in neoadjuvant chemotherapy studies [27-33] coupled with our findings support the clinical validity of the Recurrence Score test to guide neoadjuvant treatment selection of hormonal therapy or chemotherapy in postmenopausal patients with locally advanced HR + breast cancer to maximize clinical response and likelihood of BCS.

The Recurrence Score test has been repeatedly validated to predict adjuvant chemotherapy benefit [21-26]. Notably, the TAILORx (Trial Assigning IndividuaLized Options for Treatment) confirmed in the largest-ever prospective, phase 3, randomized, controlled trial in breast cancer the prognostic and predictive utility of the Recurrence Score test for node-negative breast cancer in the adjuvant setting [25]. Now the test is also validated to predict response to 
Table 3 Multivariable analysis of clinical response, controlling for clinical factors $(N=281)$

\begin{tabular}{|c|c|c|c|}
\hline Model & Variable & Odds ratio $(95 \% \mathrm{CI})$ & $p$ value* \\
\hline \multirow[t]{6}{*}{1} & ESR1 by RT-PCR (standardized) & $1.29(1.00,1.68)$ & 0.047 \\
\hline & Age (years) & $1.02(0.97,1.06)$ & 0.470 \\
\hline & Baseline tumor size $(\mathrm{mm})$ & $0.99(0.96,1.03)$ & 0.696 \\
\hline & Grade & & \\
\hline & 1 versus 3 & $0.76(0.33,1.76)$ & 0.522 \\
\hline & 2 versus 3 & $0.99(0.38,2.54)$ & 0.981 \\
\hline \multirow[t]{6}{*}{2} & $P G R$ by RT-PCR (standardized) & $1.98(1.52,2.63)$ & $<0.001$ \\
\hline & Age (years) & $1.01(0.96,1.05)$ & 0.803 \\
\hline & Baseline tumor size $(\mathrm{mm})$ & $1.00(0.96,1.04)$ & 0.976 \\
\hline & Grade & & \\
\hline & 1 versus 3 & $0.77(0.32,1.83)$ & 0.545 \\
\hline & 2 versus 3 & $1.17(0.44,3.12)$ & 0.758 \\
\hline \multirow[t]{6}{*}{3} & ER gene-group score (standardized) & $2.05(1.54,2.78)$ & $<0.001$ \\
\hline & Age (years) & $1.01(0.96,1.05)$ & 0.755 \\
\hline & Baseline tumor size $(\mathrm{mm})$ & $1.00(0.97,1.04)$ & 0.874 \\
\hline & Grade & & \\
\hline & 1 versus 3 & $0.57(0.24,1.38)$ & 0.216 \\
\hline & 2 versus 3 & $0.86(0.32,2.30)$ & 0.759 \\
\hline
\end{tabular}

$C I$ confidence interval, $E R$ estrogen receptor, $R T-P C R$ reverse transcription-polymerase chain reaction * $p$ value based on the profile likelihood test
Table 4 Association of Recurrence Score group with breast-conserving surgery candidacy before and breast-conserving surgery received after neoadjuvant letrozole

\begin{tabular}{|c|c|c|c|}
\hline $\begin{array}{l}\text { Recurrence Score } \\
\text { group }\end{array}$ & No & Yes & $p$ value* \\
\hline \multicolumn{4}{|c|}{ BCS candidacy before neoadjuvant letrozole } \\
\hline $\mathrm{RS}<18$ & $60(38 \%)$ & $97(62 \%)$ & 0.878 \\
\hline $\mathrm{RS} \geq 31$ & $20(37 \%)$ & $34(63 \%)$ & \\
\hline \multicolumn{4}{|c|}{$\mathrm{BCS}$ received ${ }^{\mathrm{a}}$ after neoadjuvant letrozole } \\
\hline $\mathrm{RS}<18$ & $31(21 \%)$ & $118(79 \%)$ & 0.009 \\
\hline $\mathrm{RS} \geq 31$ & $19(40 \%)$ & $29(60 \%)$ & \\
\hline
\end{tabular}

$B C S$ breast-conserving surgery, $R S$ Recurrence Score result

* $p$ value based on the $\chi^{2}$ test

${ }^{\mathrm{a}}$ Among patients with nonmissing information on surgery received

neoadjuvant hormonal therapy, thus demonstrating consistency in the capacity of the Recurrence Score test to guide systemic treatment decisions in both the neoadjuvant and adjuvant settings. A recent meta-analysis showed that 15 -year rates of distant recurrence and breast cancer-specific mortality, but not local recurrence, were comparable between patients who received chemotherapy in the neoadjuvant vs. adjuvant setting [37]. Therefore, the ability of clinicians to assess tumor biology earlier, at the time of core-biopsy sampling, may allow optimization of subsequent systemic treatment decisions. Along these lines, our study demonstrates the feasibility of performing Recurrence Score testing in core-biopsy samples and contributes to a body of evidence showing the practicality of using such specimens for testing [27, 31, 38, 39]. In TransNEOS, 38 of 333 (11.4\%) samples were excluded from the analysis, including $34(10.2 \%)$ for specimen-related reasons. This exclusion rate is similar to the $8.8 \%$ specimen-related failure rate observed in an analysis of core-biopsy samples tested in routine practice [38]. Use of core-biopsy samples for Recurrence Score testing may shorten the time to treatment decisions. In a recent study of early guideline-directed Recurrence Score testing, $94 \%$ of samples tested were core biopsies. Median time to treatment decision was shortened from 32 to 20 days $(p<0.001)$ [39]. As such, the feasibility of Recurrence Score testing on core-biopsy samples has the potential to minimize the lag between diagnosis and treatment initiation, although further studies are needed to determine the effect of this on clinical outcomes.

Our findings warrant further investigation of the Recurrence Score results in the neoadjuvant setting to address potential limitations. First, TransNEOS was a prospectively designed study of archived tumor samples. Bear and colleagues have already demonstrated the feasibility of using Recurrence Score results to assign neoadjuvant treatment in a prospective manner [27]. Second, the TransNEOS cohort was constrained geographically, which carries implications for the generalizability of the findings, with respect to racial/ ethnic diversity of the patient population and country-specific clinical best practices. Third, patients were selected from the 25 highest enrolling centers only. Fourth, this study did not collect information on BCS candidacy after 
neoadjuvant letrozole, only actual surgery received. Some patients may have been BCS candidates after neoadjuvant treatment but received mastectomy nonetheless because of patient preference or other reason(s). Fifth, the role of the Recurrence Score test in premenopausal patients in the neoadjuvant setting was not evaluated in TransNEOS. Results of TAILORx (adjuvant setting) showed that patients $\leq 50$ years and RS $<11$ or RS11-15 had good outcomes with endocrine therapy alone [25]. This suggests that the genomic information provided by Recurrence Score test might have utility in guiding treatment decisions in premenopausal women who are candidates for neoadjuvant therapies. Further investigations would be needed to conclude definitively.

In conclusion, TransNEOS validates the Recurrence Score result as a significant predictor of clinical response to neoadjuvant letrozole in postmenopausal women with ER+, HER2-negative, clinically node-negative breast cancer. Additional analyses may be conducted to examine the relationship between the Recurrence Score results and clinical outcomes once the parent NEOS study results become available.

Acknowledgements The authors thank Yumiko Nomura for data management support, Cindy Loman for statistical support, and Dr. Anna Lau for editorial support of manuscript development.

Funding Genomic Health provided the Recurrence Score tests for the TransNEOS study, including shipping costs. The parent NEOS study was sponsored by CSPOR (Comprehensive Support Project for Oncology Research), part of a public health research foundation. Novartis and Chugai Pharmaceuticals provided funding to CSPOR.

Data Availability Statement The datasets generated and/or analyzed for the current study are not publicly available, because of the proprietary information contained within, but are available from the corresponding author on reasonable request.

\section{Compliance with ethical standards}

Conflict of interest Hiroji Iwata: Remuneration: AstraZeneca, Chugai, Daiichi-Sankyo, Eisai, Genomic Health, Novartis, Pfizer, Taiho. Consultant/advisory role: AstraZeneca, Chugai, Daiichi-Sankyo, Kyowa Hakko Kirin, Lilly, Novartis, Pfizer. Funding: AstraZeneca, Bayer, Chugai, Daiichi-Sankyo, Eisai, GSK, Kyowa Hakko Kirin, Lily, MSD, Novartis, Pfizer. Other: CSPOR BC organizing committee member. Norikazu Masuda: Remuneration: AstraZeneca, Chugai, Pfizer, Takeda. Funding to institution: AstraZeneca, Chugai, Daiichi-Sankyo, Kyowa Hakko Kirin, Lilly, MSD, Novartis, Pfizer. Yutaka Yamamoto: Remuneration: AstraZeneca, Chugai, Daiichi-Sankyo, Eisai, Genomic Health, Kyowa Hakko Kirin, Novartis, Pfizer, Taiho, Takeda. Funding: AstraZeneca, Chugai, Novartis, Taiho. Tatsuya Toyama: Remuneration: AstraZeneca, Chugai, Daiichi-Sankyo, Eisai, Ono Pharmaceuti- cal, Taiho, Takeda. Funding: AstraZeneca, Chugai, Daiichi-Sankyo, Eisai, Kyowa Hakko Kirin, Nippon Kiyaku, Novartis, Pfizer, Taiho, Takeda. Masahiro Kashiwaba: Remuneration: AstraZeneca, Chugai, Kyowa Hakko Kirin, Novartis, Pfizer. Shoichiro Ohtani: Remuneration: Chugai, Eisai. Tomomi Fujisawa, Naruto Taira, Takehiko Sakai, Yoshie Hasegawa, Rikiya Nakamura, Hiromitsu Akabane, Yukiko Shibahara, and Hironobu Sasano: None. Takuhiro Yamaguchi: Remuneration: Daiichi-Sankyo. Consulting or advisory role: CAC Croit Corporation, Chugai, Daiichi-Sankyo, Japan Tobacco, Kowa Company, Ono Pharmaceutical, Tsumura \& Co. Funding: A2 Healthcare Corporation, AC Medical Inc., CAC Croit Corporation, Daiichi-Sankyo, FMD K\&L Japan K.K., Japan Media Corporation, Japan Tobacco Inc., Kyowa Hakko Kirin, Luminary Medical K.K., Medidata Solutions, Inc., Ono Pharmaceutical. Kentaro Sakamaki: Remuneration: Chugai, Novartis, Taiho. Travel expenses: Genomic Health. Helen Bailey: Employment and stock ownership: Genomic Health. Diana B. Cherbavaz: Stock ownership: Genomic Health. Debbie M. Jakubowski: Employment and stock ownership: Genomic Health. Naoko Sugiyama: Employment and stock ownership: Genomic Health. Calvin Chao: Employment and stock ownership: Genomic Health. Yasuo Ohashi: Remuneration: Daiichi-Sankyo, Eisai, Public Health Research Foundation, Sanofi. Research grant: Eisai. Consultant/advisory role: Chugai, Kowa, Taiho. Travel expenses: Takeda, Yakult Honsha. Other: Shionogi, Statcom.

Ethical approval All procedures performed in studies involving human participants were in accordance with the ethical standards of the institutional and/or national research committee and with the 1964 Helsinki declaration and its later amendments or comparable ethical standards. The study was reviewed and approved by each institution's review board and/or ethics committee.

Informed consent Informed consent was obtained from all individual participants included in the study.

Open Access This article is distributed under the terms of the Creative Commons Attribution 4.0 International License (http://creativeco mmons.org/licenses/by/4.0/), which permits unrestricted use, distribution, and reproduction in any medium, provided you give appropriate credit to the original author(s) and the source, provide a link to the Creative Commons license, and indicate if changes were made.

\section{References}

1. Fisher B, Brown A, Mamounas E, Wieand S, Robidoux A, Margolese RG, Cruz AB Jr, Fisher ER, Wickerham DL, Wolmark N, DeCillis A, Hoehn JL, Lees AW, Dimitrov NV (1997) Effect of preoperative chemotherapy on local-regional disease in women with operable breast cancer: findings from National Surgical Adjuvant Breast and Bowel Project B-18. J Clin Oncol 15(7):2483-2493. https://doi.org/10.1200/JCO.1997.15.7.2483

2. Makris A, Powles TJ, Ashley SE, Chang J, Hickish T, Tidy VA, Nash AG, Ford HT (1998) A reduction in the requirements for mastectomy in a randomized trial of neoadjuvant chemoendocrine therapy in primary breast cancer. Ann Oncol 9(11):1179-1184

3. Mauriac L, MacGrogan G, Avril A, Durand M, Floquet A, Debled M, Dilhuydy JM, Bonichon F (1999) Neoadjuvant chemotherapy for operable breast carcinoma larger than $3 \mathrm{~cm}$ : a unicentre randomized trial with a 124-month median follow-up. Institut Bergonie Bordeaux Groupe Sein (IBBGS). Ann Oncol 10(1):47-52

4. Mauri D, Pavlidis N, Ioannidis JP (2005) Neoadjuvant versus adjuvant systemic treatment in breast cancer: a meta-analysis. $\mathrm{J}$ 
Natl Cancer Inst 97(3):188-194. https://doi.org/10.1093/jnci/dji02 1

5. Semiglazov VF, Semiglazov VV, Dashyan GA, Ziltsova EK, Ivanov VG, Bozhok AA, Melnikova OA, Paltuev RM, Kletzel A, Berstein LM (2007) Phase 2 randomized trial of primary endocrine therapy versus chemotherapy in postmenopausal patients with estrogen receptor-positive breast cancer. Cancer 110(2):244 254. https://doi.org/10.1002/cncr.22789

6. Chia S, Swain SM, Byrd DR, Mankoff DA (2008) Locally advanced and inflammatory breast cancer. J Clin Oncol 26(5):786-790. https://doi.org/10.1200/JCO.2008.15.0243

7. von Minckwitz G, Untch M, Blohmer JU, Costa SD, Eidtmann $\mathrm{H}$, Fasching PA, Gerber B, Eiermann W, Hilfrich J, Huober J, Jackisch C, Kaufmann M, Konecny GE, Denkert C, Nekljudova V, Mehta K, Loibl S (2012) Definition and impact of pathologic complete response on prognosis after neoadjuvant chemotherapy in various intrinsic breast cancer subtypes. J Clin Oncol 30(15):1796-1804. https://doi.org/10.1200/JCO.2011.38.8595

8. Chang J, Powles TJ, Allred DC, Ashley SE, Makris A, Gregory RK, Osborne CK, Dowsett M (2000) Prediction of clinical outcome from primary tamoxifen by expression of biologic markers in breast cancer patients. Clin Cancer Res 6(2):616-621

9. Gluck S, de Snoo F, Peeters J, Stork-Sloots L, Somlo G (2013) Molecular subtyping of early-stage breast cancer identifies a group of patients who do not benefit from neoadjuvant chemotherapy. Breast Cancer Res Treat 139(3):759-767. https://doi.org/10.1007/ s10549-013-2572-4

10. Spring LM, Gupta A, Reynolds KL, Gadd MA, Ellisen LW, Isakoff SJ, Moy B, Bardia A (2016) Neoadjuvant endocrine therapy for estrogen receptor-positive breast cancer: a systematic review and meta-analysis. JAMA Oncol 2(11):1477-1486. https://doi. org/10.1001/jamaoncol.2016.1897

11. Llombart-Cussac A, Guerrero A, Galan A, Caranana V, Buch E, Rodriguez-Lescure A, Ruiz A, Fuster Diana C, Guillem Porta V (2012) Phase II trial with letrozole to maximum response as primary systemic therapy in postmenopausal patients with ER/ PgR $[+]$ operable breast cancer. Clin Transl Oncol 14(2):125-131. https://doi.org/10.1007/s12094-012-0771-9

12. Olson JA Jr, Budd GT, Carey LA, Harris LA, Esserman LJ, Fleming GF, Marcom PK, Leight GS Jr, Giuntoli T, Commean P, Bae K, Luo J, Ellis MJ (2009) Improved surgical outcomes for breast cancer patients receiving neoadjuvant aromatase inhibitor therapy: results from a multicenter phase II trial. J Am Coll Surg 208(5):906-914. https://doi.org/10.1016/j.jamcollsur g.2009.01.035. discussion $915-906$.

13. Krainick-Strobel UE, Lichtenegger W, Wallwiener D, Tulusan AH, Janicke F, Bastert G, Kiesel L, Wackwitz B, Paepke S (2008) Neoadjuvant letrozole in postmenopausal estrogen and/or progesterone receptor positive breast cancer: a phase IIb/III trial to investigate optimal duration of preoperative endocrine therapy. BMC Cancer 8:62. https://doi.org/10.1186/1471-2407-8-62

14. Eiermann W, Paepke S, Appfelstaedt J, Llombart-Cussac A, Eremin J, Vinholes J, Mauriac L, Ellis M, Lassus M, Chaudri-Ross HA, Dugan M, Borgs M, Letrozole Neo-Adjuvant Breast Cancer Study G (2001) Preoperative treatment of postmenopausal breast cancer patients with letrozole: a randomized double-blind multicenter study. Ann Oncol 12(11):1527-1532

15. Smith IE, Dowsett M, Ebbs SR, Dixon JM, Skene A, Blohmer JU, Ashley SE, Francis S, Boeddinghaus I, Walsh G, Group IT (2005) Neoadjuvant treatment of postmenopausal breast cancer with anastrozole, tamoxifen, or both in combination: the Immediate Preoperative Anastrozole, Tamoxifen, or Combined with Tamoxifen (IMPACT) multicenter double-blind randomized trial. J Clin Oncol 23(22):5108-5116. https://doi.org/10.1200/ JCO.2005.04.005
16. Ellis MJ, Coop A, Singh B, Mauriac L, Llombert-Cussac A, Janicke F, Miller WR, Evans DB, Dugan M, Brady C, Quebe-Fehling E, Borgs M (2001) Letrozole is more effective neoadjuvant endocrine therapy than tamoxifen for ErbB-1- and/or ErbB-2-positive, estrogen receptor-positive primary breast cancer: evidence from a phase III randomized trial. J Clin Oncol 19(18):3808-3816. https ://doi.org/10.1200/JCO.2001.19.18.3808

17. Toi M, Saji S, Masuda N, Kuroi K, Sato N, Takei H, Yamamoto Y, Ohno S, Yamashita H, Hisamatsu K, Aogi K, Iwata H, Takada M, Ueno T, Saji S, Chanplakorn N, Suzuki T, Sasano H (2011) Ki67 index changes, pathological response and clinical benefits in primary breast cancer patients treated with 24 weeks of aromatase inhibition. Cancer Sci 102(4):858-865. https://doi.org/10 $.1111 / \mathrm{j} .1349-7006.2011 .01867 . x$

18. Cataliotti L, Buzdar AU, Noguchi S, Bines J, Takatsuka Y, Petrakova K, Dube P, de Oliveira CT (2006) Comparison of anastrozole versus tamoxifen as preoperative therapy in postmenopausal women with hormone receptor-positive breast cancer: the PreOperative "Arimidex" Compared to Tamoxifen (PROACT) trial. Cancer 106(10):2095-2103. https://doi.org/10.1002/cncr.21872

19. Akashi-Tanaka S, Omatsu M, Shimizu C, Ando M, Terada K, Shien T, Kinoshita T, Fujiwara Y, Seki K, Hasegawa T, Fukutomi $\mathrm{T}$ (2007) Favorable outcome in patients with breast cancer in the presence of pathological response after neoadjuvant endocrine therapy. Breast 16(5):482-488. https://doi.org/10.1016/j.breas t.2007.02.003

20. Ellis MJ, Suman VJ, Hoog J, Lin L, Snider J, Prat A, Parker JS, Luo J, DeSchryver K, Allred DC, Esserman LJ, Unzeitig GW, Margenthaler J, Babiera GV, Marcom PK, Guenther JM, Watson MA, Leitch M, Hunt K, Olson JA (2011) Randomized phase II neoadjuvant comparison between letrozole, anastrozole, and exemestane for postmenopausal women with estrogen receptorrich stage 2 to 3 breast cancer: clinical and biomarker outcomes and predictive value of the baseline PAM50-based intrinsic subtype-ACOSOG Z1031. J Clin Oncol 29(17):2342-2349. https:// doi.org/10.1200/JCO.2010.31.6950

21. Paik S, Shak S, Tang G, Kim C, Baker J, Cronin M, Baehner FL, Walker MG, Watson D, Park T, Hiller W, Fisher ER, Wickerham DL, Bryant J, Wolmark N (2004) A multigene assay to predict recurrence of tamoxifen-treated, node-negative breast cancer. $\mathrm{N}$ Engl J Med 351(27):2817-2826. https://doi.org/10.1056/NEJMo a041588

22. Paik S, Tang G, Shak S, Kim C, Baker J, Kim W, Cronin M, Baehner FL, Watson D, Bryant J, Costantino JP, Geyer CE, Wickerham DL, Wolmark N (2006) Gene expression and benefit of chemotherapy in women with node-negative, estrogen receptorpositive breast cancer. J Clin Oncol 24(23):3726-3734. https:// doi.org/10.1200/JCO.2005.04.7985

23. Habel LA, Shak S, Jacobs MK, Capra A, Alexander C, Pho M, Baker J, Walker M, Watson D, Hackett J, Blick NT, Greenberg D, Fehrenbacher L, Langholz B, Quesenberry CP (2006) A population-based study of tumor gene expression and risk of breast cancer death among lymph node-negative patients. Breast Cancer Res 8(3):R25. https://doi.org/10.1186/bcr1412

24. Dowsett M, Cuzick J, Wale C, Forbes J, Mallon EA, Salter J, Quinn E, Dunbier A, Baum M, Buzdar A, Howell A, Bugarini R, Baehner FL, Shak S (2010) Prediction of risk of distant recurrence using the 21-gene recurrence score in node-negative and node-positive postmenopausal patients with breast cancer treated with anastrozole or tamoxifen: a TransATAC study. J Clin Oncol 28(11):1829-1834. https://doi.org/10.1200/JCO.2009.24.4798

25. Sparano JA, Gray RJ, Makower DF, Pritchard KI, Albain KS, Hayes DF, Geyer CE Jr, Dees EC, Goetz MP, Olson JA Jr, Lively T, Badve SS, Saphner TJ, Wagner LI, Whelan TJ, Ellis MJ, Paik S, Wood WC, Ravdin PM, Keane MM, Gomez Moreno HL, Reddy PS, Goggins TF, Mayer IA, Brufsky AM, Toppmeyer DL, 
Kaklamani VG, Berenberg JL, Abrams J, Sledge GW Jr (2018) Adjuvant chemotherapy guided by a 21-gene expression assay in breast cancer. N Engl J Med. https://doi.org/10.1056/NEJMo a1804710

26. Albain KS, Barlow WE, Shak S, Hortobagyi GN, Livingston RB, Yeh IT, Ravdin P, Bugarini R, Baehner FL, Davidson NE, Sledge GW, Winer EP, Hudis C, Ingle JN, Perez EA, Pritchard KI, Shepherd L, Gralow JR, Yoshizawa C, Allred DC, Osborne CK, Hayes DF, Breast Cancer Intergroup of North A (2010) Prognostic and predictive value of the 21-gene recurrence score assay in postmenopausal women with node-positive, oestrogen-receptor-positive breast cancer on chemotherapy: a retrospective analysis of a randomised trial. Lancet Oncol 11(1):55-65. https://doi.org/10.1016/ S1470-2045(09)70314-6

27. Bear HD, Wan W, Robidoux A, Rubin P, Limentani S, White RL Jr, Granfortuna J, Hopkins JO, Oldham D, Rodriguez A, Sing AP (2017) Using the 21-gene assay from core needle biopsies to choose neoadjuvant therapy for breast cancer: a multicenter trial. J Surg Oncol. https://doi.org/10.1002/jso.24610

28. Chang JC, Makris A, Gutierrez MC, Hilsenbeck SG, Hackett JR, Jeong J, Liu ML, Baker J, Clark-Langone K, Baehner FL, Sexton K, Mohsin S, Gray T, Alvarez L, Chamness GC, Osborne CK, Shak S (2008) Gene expression patterns in formalin-fixed, paraffin-embedded core biopsies predict docetaxel chemosensitivity in breast cancer patients. Breast Cancer Res Treat 108(2):233-240. https://doi.org/10.1007/s10549-007-9590-Z

29. Gianni L, Zambetti M, Clark K, Baker J, Cronin M, Wu J, Mariani G, Rodriguez J, Carcangiu M, Watson D, Valagussa P, Rouzier R, Symmans WF, Ross JS, Hortobagyi GN, Pusztai L, Shak S (2005) Gene expression profiles in paraffin-embedded core biopsy tissue predict response to chemotherapy in women with locally advanced breast cancer. J Clin Oncol 23(29):7265-7277. https:// doi.org/10.1200/JCO.2005.02.0818

30. Pivot X, Mansi L, Chaigneau L, Montcuquet P, Thiery-Vuillemin A, Bazan F, Dobi E, Sautiere JL, Rigenbach F, Algros MP, Butler S, Jamshidian F, Febbo P, Svedman C, Paget-Bailly S, Bonnetain F, Villanueva C (2015) In the era of genomics, should tumor size be reconsidered as a criterion for neoadjuvant chemotherapy? Oncologist 20(4):344-350. https://doi.org/10.1634/theoncolog ist.2014-0198

31. Yardley DA, Peacock NW, Shastry M, Burris HA III, Bechhold RG, Hendricks CB, Yoshizawa CN, Sing AP, Hainsworth JD (2015) A phase II trial of ixabepilone and cyclophosphamide as neoadjuvant therapy for patients with HER2-negative breast cancer: correlation of pathologic complete response with the 21-gene Recurrence Score. Breast Cancer Res Treat 154(2):299-308. https ://doi.org/10.1007/s10549-015-3613-y
32. Soran A, Bhargava R, Johnson R, Ahrendt G, Bonaventura M, Diego E, McAuliffe PF, Serrano M, Menekse E, Sezgin E, McGuire KP (2016) The impact of Oncotype DX(R) recurrence score of paraffin-embedded core biopsy tissues in predicting response to neoadjuvant chemotherapy in women with breast cancer. Breast Dis 36(2-3):65-71. https://doi.org/10.3233/BD-15019 9

33. Zelnak AB, Murali S, Styblo TM, Carlson GW, Gabram SGA, Rizzo M, Torres MA, Newell M, Liu Y, O'Regan R (2013) Phase II trial evaluating the use of 21-gene Recurrence Score to select preoperative therapy in hormone receptor-positive breast cancer. J Clin Oncol 31 (15 suppl):abstract 562

34. Akashi-Tanaka S, Shimizu C, Ando M, Shibata T, Katsumata N, Kouno T, Terada K, Shien T, Yoshida M, Hojo T, Kinoshita T, Fujiwara Y, Yoshimura K (2009) 21-gene expression profile assay on core needle biopsies predicts responses to neoadjuvant endocrine therapy in breast cancer patients. Breast 18(3):171-174. https://doi.org/10.1016/j.breast.2009.03.005

35. Ueno T, Masuda N, Yamanaka T, Saji S, Kuroi K, Sato N, Takei H, Yamamoto Y, Ohno S, Yamashita H, Hisamatsu K, Aogi K, Iwata H, Sasano H, Toi M (2014) Evaluating the 21-gene assay Recurrence Score as a predictor of clinical response to 24 weeks of neoadjuvant exemestane in estrogen receptor-positive breast cancer. Int J Clin Oncol 19(4):607-613. https://doi.org/10.1007/ s10147-013-0614-x

36. UMIN-CTR (2008) Randomized phase III study of adjuvant endocrine therapy with or without chemotherapy for postmenopausal breast cancer patients who responded to neoadjuvant letrozole. https://upload.umin.ac.jp/cgi-open-bin/ctr_e/ctr_view.cgi?recpt no $=$ R000001119. Accessed April 52018

37. Early Breast Cancer Trialists' Collaborative G (2018) Longterm outcomes for neoadjuvant versus adjuvant chemotherapy in early breast cancer: meta-analysis of individual patient data from ten randomised trials. Lancet Oncol 19 (1):27-39. https:// doi.org/10.1016/S1470-2045(17)30777-5

38. Anderson J, Shak S, Millward C, Labusch M, Chen I, Watson D, Baehner F (2009) Molecular characterization of breast cancer core biopsy specimens by gene expression analysis using standardized quantitative RT-PCR. Cancer Res 69(suppl 24):abstract 6021

39. Dzimitrowicz H, Mougalian S, Storms S, Hurd S, Chagpar AB, Killelea BK, Horowitz NR, Lannin DR, Harigopal M, Hofstatter E, DiGiovanna MP, Adelson KB, Silber A, Abu-Khalaf M, Chung G, Zaheer W, Abdelghany O, Hatzis C, Pusztai L, Sanft TB (2017) Impacts of early guideline-directed 21-gene Recurrence Score testing on adjuvant therapy decision making. J Oncol Pract:JOP2017022731. https://doi.org/10.1200/JOP.2017.022731

\section{Affiliations}

\section{Hiroji Iwata ${ }^{1}$ - Norikazu Masuda ${ }^{2} \cdot$ Yutaka Yamamoto $^{3} \cdot$ Tomomi Fujisawa $^{4} \cdot$ Tatsuya Toyama $^{5}$. Masahiro Kashiwaba ${ }^{6}$. Shoichiro Ohtani ${ }^{7} \cdot$ Naruto Taira $^{8} \cdot$ Takehiko Sakai $^{9} \cdot$ Yoshie Hasegawa $^{10} \cdot$ Rikiya Nakamura $^{11}$. Hiromitsu Akabane ${ }^{12}$. Yukiko Shibahara ${ }^{13}$. Hironobu Sasano ${ }^{13} \cdot$ Takuhiro Yamaguchi $^{13} \cdot$ Kentaro Sakamaki $^{14}$. Helen Bailey ${ }^{15}$. Diana B. Cherbavaz ${ }^{15} \cdot$ Debbie M. Jakubowski $^{15} \cdot$ Naoko Sugiyama $^{15} \cdot$ Calvin Chao $^{15} \cdot$ Yasuo Ohashi $^{16}$}

1 Aichi Cancer Center Hospital, 1-1 Kanokoden, Chikusa-ku, Nagoya, Aichi 464-0021, Japan

2 NHO Osaka National Hospital, 2-1-14 Hoenzaka, Chuo-ku, Osaka 540-0006, Japan

3 Kumamoto University, 1-1-1 Honjo, Chuo-ku, Kumamoto 860-8556, Japan
4 Gunma Prefectural Cancer Center, 617-1

Takahayashinishi-cho, Ota, Gunma 373-8550, Japan

5 Nagoya City University Graduate School of Medical Science, 1 Kawasumi, Mizuho-cho, Mizuho-ku, Nagoya, Aichi 467-8601, Japan

6 Sagara Hospital, 3-31 Matsubara-cho, Kagoshima 892-0833, Japan 
7 Hiroshima City Hiroshima Citizens Hospital, 7-33 Motomachi, Naka-ku, Hiroshima 730-8518, Japan

8 Okayama University Hospital, 2-5-1 Shikata-cho, Kita-ku, Okayama 700-8558, Japan

9 Cancer Institute Hospital of Japanese Foundation for Cancer Research, 3-8-31 Ariake, Koto-ku, Tokyo 135-8550, Japan

10 Hirosaki Municipal Hospital, 3-8-1 Oaza Omachi, Hirosaki, Aomori 036-8004, Japan

11 Chiba Cancer Center, 666-2, Nitona-cho, Chuo-ku, Chiba, Japan
12 Hokkaido P.W.F.A.C. Asahikawa-Kosei General Hospital, 24-111 Ichijo-dori, Asahikawa, Hokkaido 078-8211, Japan

13 Tohoku University Graduate School of Medicine, 1-1 Seiryo-machi, Aoba-ku, Sendai, Miyagi 980-8574, Japan

14 Graduate School of Medicine, The University of Tokyo, 7-3-1, Hongo, Bunkyo-ku, Tokyo 113-8655, Japan

15 Genomic Health, Inc., 301 Penobscot Dr, Redwood City, CA, USA

16 Chuo University, 1-13-27 Kasuga, Bunkyo-ku, Tokyo 112-8551, Japan 